\title{
Racismo e saúde: representações sociais de mulheres e profissionais sobre 0 quesito cor/raça*
} RACISM AND HEALTH: SOCIAL REPRESENTATION OF WOMEN AND PROFESSIONALS
ABOUT THE COLOR/RACE ISSUE

\author{
RACISMO Y SALUD: REPRESENTACIONES SOCIALES DE MUJERES Y PROFESIONALES \\ SOBRE LA CUESTIÓN COLOR/RAZA
}

Amália Nascimento do Sacramento ${ }^{1}$, Enilda Rosendo do Nascimento ${ }^{2}$

\section{RESUMO}

Trata-se de um estudo com abordagem multimetodológica apoiado na Teoria das Representações Sociais, com o objetivo de apreender as representações que o quesito cor tem para usuárias e profissionais de serviços públicos de saúde. Foi realizado em Unidades Básicas de Saúde do município de Salvador com 103 sujeitos. Os dados foram coletados por meio do Teste de Associação Livre de Palavras e da entrevista semiestruturada. Utilizou-se Análise Fatorial de Correspondência e análise temática. Os resultados mostram oposição de respostas entre pessoas que se autoclassificaram como brancas e pretas e oposição entre as pessoas mais jovens e mais velhas do estudo. As representações sobre o quesito cor retratam a complexidade da classificação racial e a necessidade de efetivação de trabalhos sobre políticas de saúde e de raças brasileiras.

\section{DESCRITORES}

Etnia e saúde

Política de saúde

Saúde da mulher

Enfermagem em saúde pública

\begin{abstract}
This is a multimethodology study founded on the Social Representations Theory, with the objective of aprehending the representations that the color issue has for the users and professionals of public health care services. The study was performed at Public Basic Health Units in Salvador, with 103 subjects. Data collection was performed using the Free Word-Association Test and semi-structured interviews. Factorial Correspondence Analysis and thematic analysis was used. Results showed an opposition of answers among people who classified themselves as white and black, and an opposition between the younger and older people. Representations about the color issue portray the complexity involved in racial classification and the need to implement studies on health policies and Brazilian races.
\end{abstract}

\section{DESCRIPTORS}

Ethnic group and health

Health policy

Women's health

Public health nursing

\section{RESUMEN}

Se trata de un estudio con abordaje multimétodos, apoyado en la Teoría de las Representaciones Sociales, objetivando entender las representaciones que ostenta la cuestión color para pacientes y profesionales de servicios públicos de salud. Se realizó en Unidades Básicas de Salud del municipio de Salvador, con 103 sujetos. Datos recolectados mediante Test de Asociación Libre de Palabras y de entrevista semiestructurada. Se utilizó Análisis Factorial de Correspondencia y análisis temático. Los resultados muestran oposición de respuestas entre personas autoclasificadas como blancas y negras y oposición entre las personas mayores y menores del estudio. Las representaciones sobre la cuestión color retratan la complejidad de la clasificación racial y la necesidad de efectivización de trabajos sobre políticas sanitarias y raciales brasileñas.

\section{DESCRIPTORES}

Etnia y salud

Política de salud

Salud de la mujer

Enfermería en salud pública

\footnotetext{
* Extraído da dissertação "Importância do quesito cor na assistência pré-natal: representações sociais de gestantes e profissionais", Universidade Federal da Bahia, 2006. ${ }^{1}$ Enfermeira. Mestre em Enfermagem. Professora da Universidade Federal do Recôncavo da Bahia. Cruz das Almas, BA, Brasil. amaliasacramento@hotmail.com ${ }^{2}$ Enfermeira. Doutora em Enfermagem. Professora Associada da Universidade Federal da Bahia. Salvador, BA, Brasil. enilda@ufba.br
} 


\section{INTRODUÇÃO}

As análises de questões atinentes à saúde da população brasileira têm sido enriquecidas nos últimos anos pelo crescente aporte de informações sobre a identificação racial ou da cor permitindo, inclusive, que diferentes perfis epidemiológicos sejam estabelecidos. Em muitas situações, a desagregação de dados por raça/cor revela que as pessoas negras exibem piores condições de saúde quando comparadas às brancas, seja em relação ao risco de adoecer e morrer, seja em relação às oportunidades de acesso ao cuidado.

Embora as desvantagens das pessoas negras possam ser atribuídas à pobreza, uma vez que essa parcela da população percebe os mais baixos rendimentos, especialmente as mulheres, admite-se a existência do racismo institucional responsável por desigualdades na prestação do cuidado, dentre outros aspectos.

Nesse tocante, o documento elaborado pelo Grupo de Trabalho de Saúde da População Negra da Secretaria Municipal de Saúde de Salvador/ Bahia(1) pontua que o racismo institucional se expressa tanto na relação de cuidado quanto no acesso e na própria prática institucional; cita como exemplos a forma violenta como as mulheres negras são tratadas nas maternidades, na precariedade da produção de informações com recorte racial e na dificuldade de acesso ao cuidado.

De fato, no tocante às mulheres pretas, registra-se maior risco relativo de morte na comparação com as brancas, da ordem de $7.4^{(2)}$. Estudos demostram que mulheres não-brancas tiveram mais chance de morrer por morte obstétrica direta ${ }^{(3)}$; a peregrinação em busca de atendimento no trabalho de parto tem sido mais frequente entre as mulheres negras ${ }^{(4-5)}$. Na relação de cuidado, identificou-se que as mulheres negras receberam, em média, $40 \%$ das orientações pré-natais que foram dadas às brancas ${ }^{(4)}$.

Embora tenha havido nos últimos anos uma elevação no número de estudos que tentam estabelecer relações entre a cor/raça e a ocorrência de problemas de saúde, persiste, no Brasil, certa dificuldade na obtenção da informação sobre identificação das pessoas segundo a cor/raça em documentos da área da saúde, notadamente nos prontuários.

Nesse sentido, duas situações são recorrentemente citadas: os documentos não apresentam um campo específico para registro da cor/raça, a exemplo de outros dados demográficos como idade, sexo, procedência; ou quando existe o campo para registro, a cor não é informada.

Razões de ordem metodológica e conceitual têm sido evocadas para explicar o fato. Dentre elas, questiona-se qual o modo mais adequado para coletar a informação sobre a cor/raça: se a partir da autoidentificação ou se a partir de classificação definida pela pessoa que atende a população nos serviços ou pesquisador(a). Por outro lado, a miscigenação que caracteriza a nossa sociedade põe em discussão quais pessoas podem ser consideradas negras ou brancas.

A autodeclaração parece ser a forma mais utilizada para identificação racial em saúde, sendo também aquela que, em situação de entrevista, tem sido apontada como problemática, chegando a causar constrangimento. Entretanto, esse constrangimento só se manifesta quando a pessoa entrevistada é negra ou preta.

No nosso entendimento, são as ideias e representações sobre a raça/cor predominantes em nossa sociedade que influenciam a conduta das pessoas envolvidas na obtenção dessa informação, onde as pessoas negras são consideradas inferiores em relação às brancas, gerando as desigualdades raciais.

Entretanto, no Brasil, tais desigualdades são frequentemente escamoteadas pelo mito da democracia racial, sendo a ausência e dificuldade de registro da cor nos documentos da área da saúde um dos modos de expressão das representações sociais da população sobre a raça e sobre o racismo.

Cor/raça e etnia são categorias ainda pouco valorizadas nas práticas dos serviços de saúde e nas análises da produção científica sobre a saúde no Brasil. Apenas recentemente, principalmente a partir da década de 1990, por conta das lutas dos movimentos da sociedade civil, essas categorias começaram a ser discutidas ou utilizadas nas reflexões e em modelos de atenção à saúde.

A introdução do quesito cor foi normatizada pelo Ministério da Saúde, em 1996, devendo constar em documentos importantes, tais como: declaração de nascido vivo, certidão de nascimento, carteira de identificação civil e militar, certidão de reservista, autorização de internação hospitalar $(\mathrm{AlH})$ e prontuário médico, certidão de casamento, título eleitoral, boletim de ocorrência policial, declaração de óbito e certidão de óbito(6).

Entendemos que as representações que a cor ou a raça têm para profissionais de saúde podem estar relacionadas às práticas discriminatórias de cuidado, assim como as representações de usuárias podem influenciar na busca de cuidados, pois,

a representação funciona como um sistema de interpretação da realidade que rege as relações dos indivíduos com seu meio físico e social, ela vai determinar seus comportamentos e suas práticas ${ }^{(7)}$.

É importante frisar que as representações sociais são elaboradas a partir de uma variedade de informações, de 
imagens, sentimentos conscientes e inconscientes, atitudes e não apenas por mecanismos cognitivos. Isso confere um caráter dinâmico às representações sociais e, portanto, os seus conteúdos dependem em grande medida da posição que os grupos ou indivíduos ocupam em cada sociedade $^{(8)}$. Desse modo, também as características individuais como idade, escolaridade, dentre outras, poderão promover a maior ou menor exposição das pessoas às informações ou imagens disponíveis na sociedade sobre determinados fenômenos.

Tendo, portanto, como objeto as representações sociais de usuárias de serviços públicos de saúde e de profissionais que atendem nesses serviços sobre a utilização do quesito cor nos prontuários de atendimento, os objetivos deste estudo são: apreender e analisar as representações sociais de profissionais e de usuárias sobre a raça/cor e verificar a importância atribuída por usuárias e profissionais à utilização/implementação do quesito cor nos documentos e prontuários do atendimento em saúde.

\section{REVISÃO DA LITERATURA}

A questão racial brasileira é muito complexa; é tanto antiga quanto emergente. Tal complexidade deve-se à diversificação de opiniões e metodologias acerca da classificação dos indivíduos quanto à cor/raça, bem como às ideologias que permeiam as relações raciais.

Entretanto, faz-se necessário compreender o significado de raça, cor e outros aspectos que circundam as relações sociais brasileiras para se perceber as implicações que os mesmos têm nas vidas das pessoas, tendo em vista a superação de uma série de preconceitos, discriminações e opressões que a população negra, principalmente as mulheres, estão submetidas.

A ideia de raça começou a ser difundida com mais sistematicidade no século XIX entre os cientistas europeus, sob a influência do pensamento de Charles Darwin a respeito da evolução da espécie humana.

Não há, entretanto, um conceito universal para a raça ${ }^{(9-10)}$, que tanto pode se referir a aspectos ligados à herança genética quanto às características observáveis como cor da pele, tipo do cabelo, estatura. Nisso difere do termo etnia, que surgiu após a Segunda Guerra Mundial, para indicar as diferenças de ordem cultural e religiosa que permitem caracterizar a existência de um povo, não apontando, portanto, para aspectos individuais ${ }^{(11)}$.

No Brasil, a cor é uma construção social que se estrutura em torno de uma ideologia ${ }^{(12)}$ para justificar desigualdades sociais, sendo que o padrão atual de classificação da raça tem sido preferencialmente fenotípico ${ }^{(13)}$, o que justifica, em parte, a opção pela auto-atribuição da cor em estudos e pesquisas sociais, incluindo a saúde.

A importância de estudos que abordam a questão racial, no Brasil, repousa, principalmente, no fato de que predominam ideias e representações sobre a inferioridade de pessoas negras em relação às não-negras, reproduzidas ao longo do tempo nas relações interpessoais e institucionais, caracterizando o racismo.

Enquanto o conceito de raça começou a ser mais utilizado no século XIX, o racismo, no entanto, passou a ser mais percebido, enquanto doutrina, no século $X X$, entre as duas grandes guerras mundiais, consolidando-se com a ascensão do nazismo.

O racismo pode ser entendido como uma doutrina, científica ou não, que prega a existência de raças humanas, com diferentes qualidades e habilidades, ordenadas de forma hierárquica pautando-se tanto em qualidades físicas como morais, psicológicas e intelectuais; um corpo de atitudes, preferências e gostos instruídos pela ideia de raça e de superioridade racial, seja no plano estético, físico ou intelectual ${ }^{(12)}$.

Nesse contexto, o racismo converte-se em um sistema de desigualdades de oportunidades que pode ser verificado nos vários âmbitos da sociedade, seja na educação, no emprego, na renda, na moradia, na saúde, dentre outros ${ }^{(12)}$.

A saúde, entendida como qualidade de vida, é resultante das condições de alimentação, habitação, educação, renda, meio ambiente, trabalho, transporte, emprego, lazer, acesso e posse de terra, acesso a serviços de saúde, e superação da desigualdade imputada pelo racismo; é, antes de tudo, o resultado das formas de organização social da produção, as quais podem gerar grandes desigualdades nos níveis de vida.

A saúde constitui direito inerente a qualquer cidadã ou cidadão e dever do Estado. No Brasil, representa uma grande conquista, alavancada durante toda uma trajetória de luta social no século XX. A conquista do direito à saúde foi propagada principalmente nos anos 1980 através de uma abordagem social do processo saúde-doença que culminou com a construção do SUS e capítulo especial da Constituição de 1988.

Entretanto, o alcance da saúde como bem social de toda a população independente da raça/cor ou sexo ainda não é uma realidade, pois estudos apontam maiores dificuldades de acesso de mulheres negras ao cuidado quando comparadas com não-negras, mesmo quando realizados em populações de semelhante nível de renda pessoal ou familiar ${ }^{(14)}$.

A identificação das pessoas segundo a raça/cor torna-se, desse modo, importante recurso para subsidiar políticas públicas equânimes, considerando principalmente as intersecções de gênero e raça/cor como um novo produto das relações de exclusão social. Além disso, permite identificar perfis de morbimortalidade diferenciados da população feminina, segundo a cor, dentre outros aspectos ${ }^{(6-10)}$.

O quesito cor é assunto de decreto do Ministério da Saúde do Brasil de março de 1996, que dispõe sobre a pa- 
dronização de informações sobre raça e cor dos cidadãos brasileiros e estrangeiros residentes no país, representando importante conquista do Movimento Negro ${ }^{(6)}$.

Entretanto, temos observado que a identificação da cor nos documentos de atendimento em saúde é praticamente inexistente se levarmos em conta a qualidade do registro e o método utilizado para a classificação racial( ${ }^{(6)}$. O estado atual da implantação do quesito cor revela significativas questões ligadas às características do racismo brasileiro.

O Brasil apresenta o tipo latino de relação racial diferente dos padrões raciais vigentes nos Estados Unidos e no Caribe. O Brasil e outros países latino-americanos se assemelham por compartilharem o ideal do branqueamento e o mito da democracia racial(15).

O embranquecimento ou ideal do branqueamento é entendido como um projeto nacional implementado por meio da miscigenação seletiva e políticas de povoamento e imigração europeia(16). Propunha como solução harmoniosa para o problema racial dos países latinos a desaparição gradual das pessoas negras pela via da sua absorção pela população branca.

As relações raciais na América Latina podem ser caracterizadas por um alto grau de miscigenação que favorece a criação de espaços para a manipulação da identidade étnica, e escamotear a mobilização étnica(15).

O branqueamento pode ser entendido também como uma pressão cultural exercida pela hegemonia branca, sobretudo após a abolição da escravatura, para que o negro negasse a si mesmo, no seu corpo e na sua mente, como uma espécie de condição para integrar-se na nova ordem social.

Nas populações caracterizadas por secular mistura racial, a exemplo do Brasil, Havaí e México, as formas de racismo adquirem a peculiaridade de uma existência camuflada e institucionalmente negada.

As representações sobre democracia racial, caráter harmonioso e não conflituoso das relações raciais no Brasil, começaram a ser desmontadas no campo das ciências sociais na década de 1950, quando a UNESCO patrocinou pesquisas sobre o tema dos dogmas racistas, culminando com a Declaração sobre a Raça e os Preconceitos Raciais em 27 de novembro de $1978^{(10-17)}$.

\section{MÉTODO}

Este é um estudo exploratório descritivo, com abordagem multimétodos, fundamentado na Teoria das Representações Sociais de Moscovici(8). O campo de estudo foi composto por seis Unidades Básicas de Saúde de dois Distritos Sanitários do município de Salvador, capital baiana.

Os dados foram coletados durante os primeiros seis meses do ano 2004, por meio de entrevista semiestruturada e do Teste de Associação Livre de Palavras, guiados por roteiros previamente elaborados.
O total de participantes do estudo foi de 103 , definido pelo critério de saturação, quando os temas e/ou argumentos começaram a se repetir. Desse total, 16 eram profissionais - médicas(os), nutricionistas, enfermeiras(os) e assistentes sociais - e 87 eram usuárias dos serviços de cuidados pré-natais, respondendo todas(os) ao Teste de Associação Livre de Palavras. O número de participantes da entrevista semiestruturada foi 32 , sendo 20 gestantes e 12 profissionais.

A opção por realizar o estudo com mulheres que procuraram atendimento pré-natal deveu-se à facilidade de acesso às mesmas, pois, dadas as características desse tipo de atendimento, as mulheres mantém maior contato com os serviços, seja para consultas ou exames laboratoriais e outros serviços, facilitando o agendamento das entrevistas.

As técnicas de coletas de dados foram: o Teste de Associação Livre de Palavras e a entrevista semiestruturada.

O Teste de Associação Livre de Palavras (TALP) é uma técnica projetiva, por meio da qual a estrutura psicológica do sujeito torna-se palpável pelas manifestações de condutas e reações, evocações, escolhas e criação, constituindo-se em índices reveladores do conjunto da personalidade ${ }^{(18)}$. O TALP envolve quatro condições básicas que são: estimular, tornar observável, registrar e obter a comunicação.

Os estímulos indutores neste estudo foram raça/cor e registro da cor na ficha de atendimento (prontuário), operacionalizados do seguinte modo: o TALP iniciava com as questões de identificação, sendo a cor/raça a última pergunta desse item, formulada como segue: $O$ que the veio à mente quando eu lhe perguntei a sua cor? (estímulo 1). Em seguida, perguntava-se $O$ que lhe vem à mente quando falo do registro da cor na ficha de atendimento em saúde? (estímulo 2).

A entrevista semiestruturada versou sobre as mesmas questões abordadas através do TALP sob a forma de duas perguntas dirigidas ao profissional e às usuárias, respectivamente: $O$ que representa para você perguntar $e$ registrar no prontuário a cor/raça das mulheres que você atende?, O que representa para você declarar sua cor a algum(a) profissional de saúde durante uma consulta $e$ ser registrada (a cor) no prontuário?

Quanto aos procedimentos de tratamento e análise dos dados, as informações obtidas pelo Teste de Associação de Palavras foram submetidas a tratamento estatístico, utilizando-se a Análise Fatorial de Correspondência (AFC) processada pelo Software Tri-deux-mots, versão 2.2/1995. A AFC permitiu revelar o jogo de oposições nas respostas das evocações como resposta aos estímulos indutores.

Desse modo, foram identificadas as oposições de resposta aos estímulos indutores entre os dois grupos de sujeitos (usuárias e profissionais), entre e inter-grupos, considerando as seguintes variáveis: cor, idade, escolaridade e sexo.

As entrevistas foram analisadas pela técnica de análise temática de conteúdo. 
Por se tratar de pesquisa com seres humanos, as pessoas entrevistadas autorizaram a utilização dos dados coletados por meio do Consentimento Livre e Pré Esclarecido e a pesquisa foi aprovada pelo Comitê de Ética em Pesquisa da Secretaria de Saúde do Estado da Bahia (CEP-SESAB), através do Parecer № 012/2004. Além disso, foi assegurado o anonimato das entrevistadas utilizando-se códigos que representam a ordem das entrevistas realizadas (E1 a E7).

\section{RESULTADOS}

A caracterização dos sujeitos do estudo, segundo as variáveis estudadas, indica que a maioria era constituída por usuárias (81\%), entre 20 e 34 anos (69\%) e quase todas mulheres (99\%), o que se justifica pelo fato do estudo ter sido realizado com mulheres que procuraram o serviço de pré-natal e ao fato de que as(os) profissionais existem em menor número do que a clientela. A grande maioria era também negra, representando $80,6 \%$.

Através da Análise Fatorial de Correspondência, identificou-se que, dentre as variáveis estudadas, a cor e a idade apresentaram significância estatística nas oposições de respostas evocadas pelas(os) participantes da pesquisa. Não foi identificado grupo opositor para as pessoas que se autoclassificaram como indígena. Analogamente, as representações do grupo de profissionais não apresentou seu correspondente grupo de oposição que, no caso, seria o das gestantes. Dessa forma, as oposições entre representações de gestantes e profissionais, bem como a categoria índia, não apresentaram significância estatística.

A oposição de respostas aos estímulos indutores de acordo com a cor dos sujeitos explicou $38.2 \%$ da variância total das respostas, enquanto o fator que evidencia a oposição entre as idades dos sujeitos explicou $17.9 \%$ de variância, perfazendo um total de $56.1 \%$ da variância total. Isto significa o percentual de dados contemplados estatisticamente para serem explicados.

Foram evocadas 588 palavras, mediante os estímulos indutores, existindo 194 diferentes entre si. Para o primeiro estímulo - o que lhe veio à mente quando lhe perguntei a sua cor? - as respostas das pessoas que se autoclassificaram como brancas formaram o seguinte conjunto de evocações representativas: beleza, nível social e preconceito, importante não é a cor, autodiscriminação do negro, complicado classificar e origem. Já para as pessoas que se autoclassificaram como pretas, as respostas representativas são: importante saber a cor, bom, nada, orgulho, saber motivo.

Ainda apresentando os dados referentes ao primeiro estímulo, diferenciam-se as respostas de pessoas com idades de 14 a 19 anos e aquelas que tinham 35 anos ou mais. As adolescentes apresentaram este conjunto de respostas: beleza, nível social, raça, preconceito, importante saber a cor. Entre as pessoas mais velhas, preponderaram as seguintes evocações: importante não é a cor, autodiscriminação do negro, complicado classificar, origem, nada, orgulho, saber motivo.
Nesse sentido, vê-se a oposição de respostas entre pessoas autoclassificadas como brancas e aquelas autoclassificadas como pretas. Nota-se também contraste entre o grupo mais jovem e o mais velho deste estudo, ou seja, entre adolescentes e pessoas com idade a partir de 35 anos.

No segundo estímulo - o registro da cor nas fichas de atendimento em saúde - para o grupo autoclassificado como branco, são representativas as evocações: investigar doenças, pesquisa, a cor não influencia, nível social e complicado classificar. Por outro lado, para o grupo autoclassificado como preto, são representativas as respostas: valorização, importante, normal, melhor, saber motivo e também racismo, separação, desnecessário.

Para as adolescentes, o registro da cor nas fichas de atendimento em saúde é colocado como importante e representa valorização, mas também está relacionado a preconceito, discriminação e complicado classificar, enquanto o grupo mais velho, de 35 anos e mais, representa tal registro como: investigar doenças, pesquisa, não influência, racismo, separação, desnecessário e é preciso saber motivo.

Usuárias e profissionais brancas(os) explicitaram ser de interesse o registro da cor devido à necessidade de investigar doenças, para fins de pesquisa. Referem, porém, que a cor não influencia a situação de vida das pessoas, mas sim o nível social; retratam ainda a dificuldade de identificação racial ou da cor através da expressão complicado classificar.

Por outro lado, observa-se, com base no conjunto de palavras mencionadas, um posicionamento mais consistente, tendendo mais para a aceitação da pergunta sobre cor para as pessoas que se autoclassificaram como pretas.

Entretanto, percebem-se, ainda, contradições/oposições nas palavras colocadas dentro de um mesmo grupo de pessoas, seja ele relacionado à cor autoclassificada (preta ou branca) ou relacionado à idade (adolescentes ou pessoas adultas). Vê-se, portanto, que existe, de certa forma, dificuldade nas falas dos sujeitos para um posicionamento categórico acerca do assunto cor/raça.

Os discursos das(os) participantes do estudo, captados através da entrevista, permitiram a construção dos seguintes temas de análise: a cor/raça não influencia a qualidade do cuidado ou o processo saúde/doença; o quesito cor como possibilidade de luta contra o preconceito racial; o quesito cor como fonte de discriminação e preconceito.

Os discursos ratificam e ampliam as ideias apreendidas através do TALP, complementando-se mutuamente. A representação da cor como algo que não tem influência ou importância para o atendimento e para os processos de adoecimento pode ser apreendida nos relatos abaixo:

Minhas fichas? eu nunca perguntei de cor... pra mim não influencia nada porque a cor pra mim, eu não boto nunca o quesito cor, o que eu pergunto é a idade só pra ver a gravidez de alto risco, mas a cor pra mim não influencia 
em nada porque a orientação é a mesma, eu que implantei a ficha, revisei a ficha e nunca coloquei o quesito cor, a idade $\operatorname{sim} . . .(E 1)$.

Não tem muito significado não, não tem muito a ver, eu acho que teria que acrescentar, na minha opinião, é o nível de escolaridade, que não tem ainda, é como vive socialmente, a sua renda familiar, porque isso vai influenciar a sua maneira de transitar durante esse período de gestação [...] (E2).

Discriminar a cor da pessoa? Eu não acho preciso. Qual a cor que você me vê? Não existe importância nenhuma, cor, o quesito cor, qual a importância que tem? Discriminar assim a cor da pessoa, tem que discriminar a doença, o que a pessoa está sentindo, mas a cor, não vejo importância (E3).

O segundo tema suscitado pela questão do registro da cor/raça nos prontuários refere-se à implantação/utilização do quesito cor como uma ação positiva, ancorada no pensamento de se reverter em benefício para a população de forma geral, traduzida em conscientização, aprendizagem, engajamento em lutas e movimentos sociais e, ainda, uma visão global de melhora do país, para a adoção de novos valores, como respeito à alteridade:

Eu acho válido porque as pessoas se autoidentificam e procuram até se engajar nas lutas, né, buscar suas dificuldades, entrar nas lutas para que essas dificuldades venham a diminuir, então eu acho super importante isso... (E4).

Eu acho que as pessoas têm que lutar para isso acontecer... acho boa ideia, pelo menos vai influenciar mais pessoas, as pessoas vão tomar mais atitude, porque, geralmente, as pessoas negras, eles, às vezes querem fazer alguma coisa, mas ficam pensando, será que vai dar certo, já é uma coisa que você, já dá um passo mais na frente... (E5).

Eu acho bom, uma maneira de como o Ministério está fazendo com que o nosso país melhore, em respeito a nossa raça, não é? E a gente vê que ainda existe muito preconceito sobre a nossa raça, branco, preto, amarelo, existe preconceito, então eu acho bom, uma maneira de as pessoas se entenderem melhor como ser humano... (E6).

Uma das nuances que pode dificultar o estímulo à implantação do quesito cor, tanto para profissionais quanto para gestantes, está inscrita no constrangimento que o questionamento pode provocar, tanto para quem entrevista quanto para quem responde à indagação. No relato de uma das entrevistadas, atribui-se o constrangimento à possibilidade do fato ser usado para discriminar ou fomentar atitudes preconceituosas. Talvez por isso algumas evocações apreendidas através do TALP vinculam a questão da utilização do quesito cor a saber o motivo da pergunta. Por outro lado, esse constrangimento está vinculado ao método de coleta da informação sobre a cor, por meio da autoatribuição de pertença racial, como é possível depreender-se do relato abaixo (Entrevistada 7):
Eu me sentiria muito mal, entendeu? Em sendo profissional e estar com a ficha do paciente, perguntar pra ele, porque isso, num país como o nosso, onde a discriminação existe, entende? Eu não sei como a pessoa vai reagir, entendeu, se ela tiver uma relação muito boa com a sua cor, ela vai tirar isso de letra, e se ela não tiver? E se ela já tiver sido vítima do preconceito? Ou se ela sabe que a situação que ela vive é em decorrência do preconceito?... Será que ela não estará vendo em mim também um, não sei... Eu não me sentiria bem fazendo isso não, sinceramente (E7).

\section{DISCUSSÃO}

Observa-se uma oposição entre as respostas das pessoas que se denominaram brancas e das que se denominaram pretas. Verifica-se que a questão cor não é valorizada pelo grupo branco, pois, para ele, a cor não é importante para determinar as condições de vida das pessoas, e sim sua classe social, referenciada no TALP como nível social. Além disso, é bem representada a ideia de que as pessoas brancas pensam a questão racial como um problema apenas das pessoas negras, quando se vê representativa a evocação da expressão autodiscriminação do negro, ao serem estimuladas pela pergunta sobre cor.

Esse posicionamento quanto à autodiscriminação do negro é retratado por autoras(es) brasileiras(os), sendo uma das grandes tônicas nos discursos sobre preconceito no Brasil. Discute-se que as projeções valorativas do branco ganharam prestígio na consciência do negro em detrimento das projeções de seu próprio valor. Os reflexos disso se expressam nas mais diversas atitudes das pessoas negras, conscientemente ou não, de violência para consigo mesmas, de não-aceitação ou tentativas de alterar seus próprios traços físicos e negar as origens culturais ${ }^{(16-20)}$.

Esses sentimentos advêm de um processo histórico-cultural em que o branqueamento é entendido pela sociedade como uma espécie de condição para se integrar a uma nova classe social, hegemonicamente branca ${ }^{(16)}$.

Frisa-se também a forma como as pessoas negras referem saber o motivo de ser questionado sobre cor, explicitando fortemente a necessidade de que a introdução do quesito cor em qualquer atendimento deve ser precedida de uma conscientização/sensibilização bastante planejada para com a população de forma geral.

Entender o motivo de estar sendo questionado sobre cor pode envolver um resultado positivo no engajamento na luta contra a discriminação negativa. Tal reflexão é bem retratada por outros autores:

Já os seres humanos precisam saber com rigor e responsabilidade social por que estão sendo inquiridos sobre algo que os afeta profundamente em todas as dimensões da sua vida, por que nomeá-lo e, principalmente, por que este ato invasivo, no país da suposta democracia racial, pode transformar-se numa arma poderosa na luta pela igualdade e pela educação anti-racista ${ }^{(13)}$. 
Para as(os) jovens do estudo, há duas distintas representações para a pergunta sobre a cor: a que supõe uma ordem positiva da resposta, referida como beleza e raça, e outra que supõe uma ordem negativa, referindo-se à cor como preconceito.

Para as pessoas de maior idade, entretanto, a pergunta sobre cor remonta às origens (que traz a condensação de palavras como ancestrais e raízes), revelando ainda que é complicada a classificação das pessoas quanto à cor/raça.

Essa dificuldade de classificação percebida pelos sujeitos do estudo remete às reflexões nos processos de auto e heteroidentificação da cor no Brasil. Esta complexidade deve-se à diversificação que existe na classificação dos indivíduos sobre cor/raça, bem como à ideologia que permeia o pensar a classificação racial, se com um olhar fenotípico ou com um olhar na origem, descendência ${ }^{(20)}$.

A coleta da cor no Brasil também sempre foi envolvida por complexidades, desencadeando sempre instabilidades e embaraços para coletores e declarantes. Entre atribuir a cor e dar nome a ela ocorrem inúmeros fatores determinados pela condição social, regional e outras. A complexidade principal parece concentrar-se na relação estabelecida entre coletor e declarante ou nomeado ${ }^{(13)}$.

Vê-se que tanto a pergunta sobre cor quanto seu registro no atendimento em saúde não tem expressão significativa para as pessoas brancas. Apesar de referirem alguns objetivos possíveis (investigar doenças e pesquisa), não aprovam o quesito cor como categoria importante e valorizam mais a situação sócio-econômica ao evocar o nível social como resposta.

Para a investigação de doenças retratada pelos sujeitos, outros autores apontam essa importância, afirmando que o recorte racial na saúde é um dado epidemiológico essencial, pois permite visibilizar as doenças que aparecem mais ou são exclusivas de determinados grupos como negros, brancos, amarelos, judeus, ciganos etc. e em mestiços de tais grupos, de modo que se possa interferir na realidade, diminuindo as desigualdades sociais ${ }^{(10)}$.

Com relação à classe e nível social, concorda-se com afirmativas já descritas na literatura brasileira, pois tentar

\section{REFERÊNCIAS}

1. Salvador. Secretaria Municipal de Saúde; Grupo de Trabalho de Saúde da População Negra. Diagnóstico de saúde da população negra de Salvador. Salvador; 2006.

2. Martins AL. Mulheres negras e mortalidade materna no estado do Paraná, de 1993 a 1998 [dissertação]. Ponta Grossa: Universidade Estadual de Ponta Grossa; 2000. diluir o debate sobre raça/cor, analisando apenas a classe social, é uma saída de emergência permanentemente utilizada, embora todos os mapas que comparam a situação dos trabalhadores negros e brancos nos últimos 20 anos explicitem, entre os trabalhadores, pobres e negros, um déficit muito maior em todas as dimensões da vida na saúde, na educação, no trabalho. O jargão repetitivo é que o problema limita-se à classe social. A classe social é importante, mas é preciso articulá-la com outras categorias, como por exemplo, sexo, idade e cor/raça ${ }^{(16)}$. Para as pessoas de cor preta, entretanto, a representação do quesito cor revela-se como uma situação polêmica, com antônimas significações. Assim, tanto é referido como normal perguntar a cor, como está associado a racismo, separação e desnecessário.

\section{CONCLUSÃO}

As abordagens trazidas pelos sujeitos, revelando o quesito cor como uma questão ainda complexa, sinaliza a importância de se iniciar um trabalho sólido e concreto para uma conscientização e sensibilização da população sobre as questões raciais, para uma educação antirracista efetiva, com caráter multidisciplinar; uma luta antirracista nas escolas, nos centros de saúde e hospitais, nas academias e mais efetivamente nos movimentos sociais. Assim, significa uma luta contra a falta de indignação da população para com as formas sutis e bruscas de racismo que acontecem, de fato, em nossa sociedade.

Dentre outras categorias, cor/etnia, gênero, processo saúde-doença, educação, nível socioeconômico, possuem uma inter-relação e manifestam-se na vida dos grupos populacionais e indivíduos em graus e modos diversos. Por conta disso, é de extrema relevância a incorporação destas categorias como dimensões de análise nos estudos dos processos de morbidade e mortalidade e das desigualdades sociais.

Essa incorporação deve, portanto, fazer parte das investigações das ciências sociais e da saúde que devem aprofundar os conhecimentos sobre as múltiplas interfaces dos efeitos da dimensão étnico-racial sobre a saúde.

3. Marinho ACN, Paes NA. Maternal mortality in the state of Paraíba-Brazil: association between variables. Rev Esc Enferm USP [Internet]. 2010 [cited 2010 Nov 16];44(3):732-8. Available from: http://www.scielo.br/pdf/reeusp/v44n3/en_26.pdf

4. Leal MC, Gama SGN, Cunha CB. Desigualdades raciais, sócio-demográficas e na assistência pré-natal e ao parto. Rev Saúde Pública. 2005;39(1):100-7. 
5. Tanaka ACA. Maternidade: dilema entre nascimento e morte. São Paulo: Hucitec; 1998.

6. Barbosa MI. Racismo e saúde [tese doutorado]. São Paulo: Faculdade de Saúde Pública, Universidade de São Paulo; 1988.

7. Abric JC. A abordagem estrutural das representações sociais. In: Moreira ASP, Oliveira DC, organizadoras. Estudos interdisciplinares de representação social. Goiânia: AB;1998. p. 27-38.

8. Moscovici S. Representação social da psicanálise. Rio de Janeiro: Zahar; 1978.

9. Schwarcz LM. O espetáculo das raças: cientistas, instituições e questão racial no Brasil, 1870-1930. São Paulo: Companhia das Letras; 1993.

10. Oliveira F. Saúde da população negra: Brasil ano 2001. Brasília: OPAS; 2003.

11. Banton M. A ideia de raça. Lisboa: Edições 70; 1977.

12. Guimarães ASA. Cor, classes e status nos estudos de Pierson, Azevedo e Harris na Bahia: 1940-1960. In: Maio MC, Santos RV, organizadores. Raça, ciência e sociedade. Rio de Janeiro: FIOCRUZ; 1996. p. 143-57.

13. Piza E. O baile da cor: apontamentos sobre conceitos, métodos e procedimentos de classificação racial. In: Silva Junior $\mathrm{H}$, organizador. O papel da cor raça/etnia nas políticas públicas de promoção da igualdade: anotações sobre a experiência do município de Santo André. São Paulo: CEERT; 2003. p. 62-74.

14. Nascimento ER, Ferreira SL. Desigualdades raciais no acesso à assistência em saúde: um estudo comparativo entre muIheres. In: Resumos da 2a Jornada Australes Interdisciplinares Mujer y Desarollo: Constuyendo el Derecho a la Igualdad; 2001 set. 13-15; Valdivia, Chile. Valdivia: Universidade Austral de Chile; 2001. p. 18.
15. Hasenbalg C. Entre o mito e os fatos: racismo e relações raciais no Brasil. In: Maio MC, Santos RV, organizadores. Raça, ciência e sociedade. Rio de Janeiro: FIOCRUZ; 1996. p. 235-49.

16. Carone I, Bento MAS. Psicologia social do racismo: estudos sobre branquitude e branqueamento no Brasil. Petrópolis: Vozes; 2002.

17. Organização das Nações Unidas para a Educação, Ciência e Cultura. Declaração sobre raças e os preconceitos raciais [Internet]. Paris; 1978 [citado 2010 nov. 16]. Disponível em: http://www.dhnet.org.br/direitos/sip/onu/discrimina/ dec78.htm

18. Nóbrega SM, Coutinho MPL. O teste de associação livre de palavras. In: Coutinho MPL, Lima AS, Oliveira FB, Fortunato $M L$, organizadores. Representações sociais: abordagem interdisciplinar. João Pessoa: Ed. UFPB; 2003. p. 89-97.

19. Azevedo E. Raça: conceito e preconceito. São Paulo: Ática; 1987.

20. Rafael AS. Perguntar a cor e raça é racismo? O impacto da autoclassificação na rotina de um Serviço de Saúde Pública em São Paulo. Bol Inst Saúde Raça Etnia Saúde [Internet]. 2003 [citado 2010 nov. 16];(31):31. Disponível em: http://www.isaude.sp.gov.br/smartsitephp/media/isaude/file/bis/bis31.pdf

21. Rosemberg F, Piza E. Cor nos censos brasileiros. In: Carone I, Bento MAS, organizadores. Psicologia social do racismo: estudos sobre branquitude e branqueamento no Brasil. Petrópolis: Vozes; 2002. p. 91-120.

Apoio: Conselho Nacional de Desenvolvimento Científico e Tecnológico - CNPq. 